\title{
LA TELEVISIÓN, MANO AMIGA Y ENEMIGA
}

Pura Raya González: Escuela Superior de Comunicación de Granada (España)

\section{Introducción}

La televisión, según algunos comunicólogos, no es buena maestra. Sin embargo, en general, los medios de comunicación, también contribuyen a afianzar en nosotros valores que, inculcados desde la escuela y la familia, nos hacen ser mejores personas. Lo que nadie duda es que estos, los mass media, considerados el cuarto poder, condicionan el comportamiento social y contribuyen a la creación de la realidad colectiva, especialmente en lo que respecta a las situaciones que no vivimos y que nos llegan a través de ellos. ${ }^{1}$

Para comprender esta breve reflexión, cómo la televisión puede ser al mismo tiempo nuestra amiga y enemiga, analizaremos en el presente capítulo los principales elementos que posibilitan todo proceso de comunicación y, por tanto, alimentan esa «relación amor-odio», objeto de gran debate en los últimos años.

\section{El emisor}

Ser periodista es, por muchos aspectos, una suerte, un privilegio. Pero, trabajar en los medios de comunicación exige un grado de responsabilidad mayor del que imaginamos. Una compañera de oficio, Lola Domínguez, dijo en una ocasión que el periodismo es la única profesión que permite verlo todo de cara, que hace posible mirar de tú a tú a la realidad y asistir al espectáculo de la vida en primera fila. Y así es, porque los hechos que se narran, los protagonistas de las historias que son noticia, los escenarios que capta el objetivo de una cámara de fotografía o vídeo y hasta los momentos que se respiran junto a otros profesionales te dan, en numerosas ocasiones, una lección de vida y conforman en el corazón del periodista un recuerdo indeleble. Compartir con alguien la recepción de un órgano, la adopción de un niño, la satisfacción que provoca salvar la vida a otro o ayudar a una familia sin recursos son sólo algunos ejemplos. También, asistir a la llegada de una patera a puerto, al despido de todo un colectivo obrero o al desahucio de unos vecinos moldea nuestro yo, nos enseña.

El periodista, por tanto, aprende en su quehacer diario de las alegrías y desgracias de otros y más ahora con la eclosión de nuevos formatos televisivos que exigen a los reporteros estar más cerca de las historias y sus protagonistas para sentir su desdicha o gozo y contagiar al que observa desde casa. Otros programas, incluso, han llegado a convertir al profesional del medio en protagonista, en garante de las

Terán Giménez de Cisneros, Rafael J, "Solidaridad y medios de comunicación”, en Comunicar, $\mathrm{n}^{\circ}$ 15, 2000. Págs. 29-35.

Recibido: 01/03/2005---Aceptado: 16/04/2005---Publicado: 12/11/2005 
consecuencias de numerosos fenómenos sociales como la drogadicción, la indigencia o la anorexia, entre otros. Informar desde la experiencia, en definitiva.

Pero, que el periodista sienta, tome conciencia, y actúe, no es suficiente, con eso no basta, pues su responsabilidad estriba en trasladar esos valores a la sociedad. Su misión de mediador exige un compromiso, especialmente cuando se trabaja en un medio público. Sin embargo, ¿este principio se cumple o es sólo una quimera? La naturaleza intrínseca de un medio como la televisión, unido a los intereses económicos e ideológicos que imperan en cualquier empresa mediática tienen mucho que decir al respecto, pues arbitran no sólo lo que se dice sino cómo se dice. Son el director de orquesta de un conjunto de intérpretes que si no quieren desentonar con sus instrumentos han de rendirse ante los pies de una batuta que, a veces, se salta la partitura.

La famosa teoría del espejo, el hecho de creer que los mass media son un fiel reflejo de la realidad y la objetividad un tótem infranqueable del periodismo, forma ya parte de un lejano pasado. La línea editorial de cada grupo de comunicación y los ingredientes políticos y empresariales que fagocitan el desempeño de la profesión son, en la mayoría de las ocasiones, la antesala de un mensaje dirigido, totalmente arbitrado, contaminado y sesgado, celoso de la reflexión de un receptor cada vez más activo, exigente y reflexivo.

Pero no todo queda ahí. La constante toma de decisiones persigue al periodista en su desempeño diario y es precisamente esa incesante elección la que explica muchas de las anotaciones contempladas hasta estas líneas. El profesional de los medios decide qué hechos cubrir y cuáles no, a qué fuentes informativas acudir, qué localizaciones y planos mostrar, el enfoque del tema, las declaraciones que seleccionar, el léxico, el género informativo, el espacio y la jerarquización del hecho dentro de la escaleta de radio o televisión o de la página de un periódico, tanto en papel como digital. Eso, sin contar con que cada redactor atesora unos valores y principios y tiene una percepción del mundo única e irrepetible que, sin duda, subyacerán en el producto final. Por último, la presión del tiempo y el espacio inherentes a esta profesión, los recortes de plantilla acaecidos durante los últimos años, y con ello la ausencia de especialización y la aparición del periodista "todo terreno" o multitarea, y la presión de los índices de audiencia de la competencia merman la capacidad para contrastar la información y elaborarla con todo el rigor que merece. Y es así como llegamos a la construcción del mensaje.

\section{El mensaje}

Informar, formar y entretener son las principales funciones que, según Lasswell, cumple la televisión. Pero, tanto en un caso como en el resto, los objetivos del medio y de sus profesionales son claros: atrapar la atención del espectador y calar en él con sus contenidos. Hubo quien llegó a decir que una noticia es buena si consigue que el receptor, mientras desayuna, deja de llevarse el cruasán a la boca para depositar todos sus sentidos en lo que ve y escucha. Por su parte, Carl Warren definió los elementos que confieren noticiabilidad a un hecho: actualidad, proximidad, prominencia, curiosidad, conflicto, suspense, emoción y consecuencias. Porque lo que suscita el interés del público es aquello que acaba de ocurrir, nos 
resulta cercano y curioso, es notorio, tiene repercusiones y nos deja con ganas de más, pero, de manera especial, lo que entronca con nuestros sentimientos y remueve nuestra conciencia. $^{2}$

En este sentido, y en referencia a la solidaridad, los medios de comunicación, principalmente la televisión, nos muestran las alegrías humanas, pero también las tristezas: la destrucción, la marginalidad, la exclusión, la muerte, las hecatombes nacionales. Toda una serie de contextos que nos obligan a la práctica de la acción solidaria. Estas situaciones tan traumáticas nos llevan a empatizar, a ponernos en el lugar de los otros.

Es un tipo de experiencia donde la gratuidad debe renovarse día a día, porque las necesidades humanas son inmensas y múltiples. Además, nos acerca las imágenes con todos sus claroscuros a las esferas de lo próximo, de lo cercano. Estamos obligados a recrear el valor de los mundos que aparecen en las pantallas y sus esferas de proximidad. Los problemas cercanos, aquellos que percibimos a nuestro lado, son los que nos ayudan a potenciar la solidaridad como una especie de compromiso militante a favor de los demás/otros. ${ }^{3}$

En este sentido, la televisión es una ventana abierta al mundo desde la que se observa con detalle hasta el horizonte más lejano. El poder del directo, vivir la historia a tiempo real, la fuerza de la imagen y la tendencia en los últimos años a personalizar las noticias, a elegir a personas con nombres y apellidos para explicar hechos de muy diversa índole, soplan a favor de hacer mella en el telespectador, sensibilizarlo, emocionarlo, conmoverlo, concienciarlo. No obstante, los grandes medios de comunicación, salvo excepciones, contribuyen en gran medida a extender una imagen negativa, alimentando prejuicios y estereotipos preexistentes. "Un adjetivo, un matiz en un titular, una determinada imagen, un artículo de opinión, etcétera, pueden hacer mucho daño o beneficio a la hora de informar-formar la conciencia de los ciudadanos". ${ }^{4}$

Por otra parte, y como añade el mismo autor, Tabares Carrasco, "los medios estimulan las fibras sensibles y logran sacar las mejores acciones solidarias del público, pero son actos pasajeros, efímeros". ${ }^{5}$ Nos conmueven historias de los más necesitados, de quienes padecen una catástrofe natural, precisan de un trasplante de órganos, ignoran el paradero de un ser querido o reclaman dinero para poder someterse a una intervención quirúrgica en la que se le va la vida, pero, ¿qué es ahora de ellas? ¿Y de esos sujetos que gritan auxilio? ¿Ya no es necesaria nuestra ayuda? Está claro que estas noticias que nos traquetean el alma, se nos olvidan cuando dejan de aparecer en el periódico, la radio o la televisión y, es más, nos

\footnotetext{
2 Grijelmo, Álex; Negredo, Samuel, El estilo del periodista, Ed. Taurus, 2003. Madrid.

3 Froufe Quintas, Sindo, "Solidaridad y medios de comunicación: hacia una pirámide de colaboración", en Aula, no 10, 1998. pág. 191.

Tabares Carrasco, Esteban, "Medios de comunicación, ¿instrumentos para la solidaridad?", en Comunicar, no 15, 2000. Pág. 32.

Tabares Carrasco, Esteban, “Medios de comunicación, ¿iinstrumentos para la solidaridad?”
} 
emocionan pero no nos invitan a mantener un compromiso solidario estable. Igual que llegan, se van.

Esteban Tabares Carrasco designa a esto solidaridad como espectáculo, es decir, lanzar mensajes que provocan reacciones emocionales en las gentes, que existen en la medida en que aparecen o desaparecen como noticia en los informativos y que casi nunca aparejan un análisis de los mismos, sino que enmascaran frívolamente sus causas y sus causantes. Además, afirma que actualmente se practican tres tipos de solidaridad en el planeta: ${ }^{6}$

1. Solidaridad como campaña, en la que normalmente intervienen ONG.

2. Solidaridad como cooperación, cuando los más ricos ayudan a los más pobres.

3. Solidaridad como encuentro que provoca un cambio de talante personal o actitud vital y que queda profunda y permanentemente afectado por la miseria ajena, aunque siendo cada vez más impermeables. Tal vez seamos ciegos que, viendo no ven, pues teniendo la realidad del mundo a nuestro alcance a través de la televisión parecemos estar curados de espantos. ${ }^{7}$

Dicha inmunización responde, en buena parte, a la tendencia en la última década de 'maquillar' las noticias con morbo, adecentando exageradamente los vídeos con tintes amarillistas, conduciendo las situaciones y acciones hacia la teatralización y, por consiguiente, banalizando y hasta frivolizando, en muchos casos, asuntos de peso social.

En esta línea, recuerdo cuando el periodista y presentador de Canal Sur Fernando Díaz de la Guardia proyectó durante un curso celebrado en Granada bajo el título El rostro audiovisual de la solidaridad un vídeo que mostraba con auténtica crudeza el día a día de una señora enferma que pedía ayuda en el programa Andalucía Directo, de Canal Sur TV. Los planos que dejaban al descubierto el lamentable estado de salud de la mujer y las secuelas físicas que la patología marcó sin escrúpulos en su cuerpo decían mucho de la ética profesional de quienes elaboraron el reportaje. Como muy bien señaló Díaz de la Guardia, no era necesario ni requisito indispensable ilustrar de tal forma el problema de esa andaluza, cuando lo importante era el mensaje de auxilio que lanzaba. Aunque, desde luego, logró que, desde sus hogares, los televidentes empatizaran con ella y se lanzaran a apoyarla.

Hemos llegado a un punto en que, quizá, haya que pisar a fondo el freno y reflexionar sobre los códigos deontológicos que rigen el desempeño de la profesión periodística. Es cierto que ya se están dando pasos en este sentido, pues hay asociaciones que defienden al telespectador y organismos que velan por el cumplimiento de dichas normas éticas.

A pesar de estos avances, tampoco hay que pasar por alto una cuestión. Cada medio, al igual que cada periodista, trata de manera distinta un mismo asunto. Con

Tabares Carrasco, Esteban, "Medios de comunicación, ¿instrumentos para la solidaridad?"

Zubero, Imanol, "Las nuevas condiciones de la solidaridad", en Comunicar, no 15, 2000. Págs. 15-20. 
una materia prima compartida, con ingredientes idénticos, cada cual elabora su "menú" con la intención inequívoca de "conquistar" el "paladar" de sus "comensales".

\section{El medio y el canal}

La televisión es un medio de comunicación que se caracteriza por su efecto narcotizador o, como lo denominan los expertos, "efecto primming". Por eso, conviene trabajar duro en la alfabetización mediática desde la familia y la escuela para huir de la recepción pasiva y hacer de las generaciones futuras telespectadores reflexivos, críticos y con una actitud solidaria arraigada. Los mass media, como ya se ha resaltado, son grandes difusores de cultura y valores, pero siempre que sean bien utilizados, pues llegan a todos los rincones y tienen una influencia decisiva en la construcción de nuestra persona.

Sólo tiene sentido preguntarse cómo podrían contribuir los medios de comunicación al desarrollo de la solidaridad si partimos de la idea de que estos ejercen en la sociedad un notable poder, extendiendo su influencia a diversas esferas y aspectos de la vida social.

Los medios, que inciden en la percepción que tiene el ciudadano del entorno, de sí mismo y de los demás, pueden socializar políticamente a la población, sensibilizar a la opinión pública, crear conciencia social y contribuir a su educación, y del mismo modo que pueden ayudar a construir una sociedad democrática donde se deslegitimen conductas intolerantes, pueden ser transmisores de valores, estereotipos y prejuicios [...] podrían estar al servicio de la solidaridad, del mismo modo que contra ella. ${ }^{8}$

Así pues, la televisión está contribuyendo a derribar barreras de nacionalidad o raza que nos permitían dividir nuestro espacio moral entre las personas pero que, por otro lado, "la televisión presenta, como Jano, una segunda y preocupante faz que nos convierte en voyeurs de un sufrimiento ajeno, en turistas de un paisaje de angustia, y nos enfrenta con sus destinos, al tiempo que esconde las distancia".

Merece especial atención, en este sentido, la audiencia más joven, que tiende a consumir lo que recibe de los medios sin digerirlo lo suficiente y que, en especial, cuando se trata de series de ficción, no tarda en identificarse con alguno de los personajes, soñando ser, vestir, pensar y actuar como ellos. Este hecho entraña peligro desde hace unos años y ya son numerosos los estudios dirigidos a analizar este fenómeno, más aún, cuando los guiones de estos contenidos televisivos dibujan a adolescentes no precisamente caracterizados por un talante solidario. Las drogas, el sexo, la violencia y la intolerancia son señas de identidad de muchas de estas series seguidas con tanto fervor por la juventud española de la última década.

\footnotetext{
8 Gualda Caballero, Estrella, "Solidaridad y medios de comunicación: una difícil articulación", en Comunicar, nº 15, 2000. Pág. 23.

9 Ignitieff, M, El honor del guerrero. Guerra étnica y conciencia moderna, Ed. Taurus, 1997. Madrid.
}

Pág. 24. 
Llegados a este punto, cabe preguntarse por qué las grandes cadenas encajan estos contenidos en sus parrillas. ¿Porque saben que su éxito está garantizado y, por consiguiente, como empresas que son, superponen la rentabilidad económica a la ética profesional?

La realidad es que las cadenas de televisión mantienen una batalla diaria por los índices de audiencia. Luchan por quedar las primeras en el ranking, combaten sin compasión contra la competencia y, desde los puestos de dirección, presionan a diario a todo el equipo humano que hace posible la emisión de contenidos.

Son muchos los comunicólogos que subrayan el cambio que ha dado la televisión en unos años. Mientras que en los cincuenta sus pretensiones eran mayormente culturales, a partir de los noventa aboga por explotar los gustos del gran público para alcanzar la audiencia más amplia posible ofreciendo a los telespectadores productos basados en la exhibición de experiencias vividas, a veces extremas, para satisfacer una necesidad de voyeurismo" y, yo me atrevería a añadir, de panoptismo o ver sin ser visto. El problema es que la audiencia está ahí, detrás de los datos que avalan la continuación de ese tipo de espacios.

\section{El receptor}

El ser humano descubrió en la televisión esa ventana abierta al mundo que forma, informa y entretiene, con un alto poder anestésico y manipulador, y con enormes dotes de conquista. Con la amenaza de Internet durante los últimos años, la pequeña pantalla se ha llevado siempre la palma entre los medios de comunicación a los que se dedican más horas de tiempo libre.

"En la era de la sobre información y el ciberespacio, según Ignacio Ramonet, dos parámetros ejercen la influencia determinante sobre la información: el mimetismo mediático y la hiper-emoción". ${ }^{10}$ Es decir, los contenidos que ofrece la televisión, en cuanto a imágenes, tratamiento, léxico o fuentes, tiende a homogeneizarse. En todas las cadenas emiten lo mismo y juegan con imágenes de marca solidaria, consideradas para todos los gustos, pues interesan a la mayor parte de la audiencia y, cuanto menos, la conmueven. $Y$ es entonces cuando aflora la hiper-emoción, o lo que es lo mismo, la empatía del televidente hacia el protagonista de los hechos.

Y lo mismo ocurre con la publicidad, de la que vive realmente la televisión. A día de hoy, resulta muy difícil sustraerse de la publicidad solidaria, presente en cualquier rincón por el que pisamos: en los productos de belleza y alimentación, en vallas y marquesinas... Pero, no hay que olvidar que la publicidad no sólo lanza mensajes dirigidos a la concienciación social, sino también al consumismo, y eso convierte a los ciudadanos en seres insolidarios que sólo piensan en tener el último móvil u ordenador que ha salido al mercado, por citar algunas de las tendencias del consumidor del siglo XXI.

Como se expuso anteriormente, el reto está en ser un receptor crítico, pues, "el mosaico de iconos y opiniones que se perciben ofrece información, pero hay que

10 Díez Rodríguez, Ángeles, "Medios de comunicación y el espectáculo de la miseria", en Pueblos, 2001.

Pág. 3. 
cribarla, analizarla, unirla a otras fuentes de información y de opinión, y al final, personal y colectivamente tomar partido, optar, asegurar la propia reflexión y actuar en consecuencia". ${ }^{11}$ En definitiva, la televisión no puede perder su función educadora, formativa y reflexiva.

\section{Conclusiones}

Es una realidad innegable que los medios de comunicación inciden de manera considerable en nuestro comportamiento y nuestros principios, actuando, muchas veces, como timón de nuestra personalidad. El poder que ejercen sobre las personas todos ellos, en particular la televisión, es colosal, lo que está íntimamente relacionado con la credibilidad y el valor que el ciudadano otorga a cualquier contenido por el hecho de ser proyectado en la pequeña pantalla, emitido en una cadena de radio o publicado en un periódico. Pero, como venimos preguntándonos, ¿esta sobrevaloración compartida es beneficiosa o perjudicial para ambas partes? ¿Qué consecuencias tiene?

En su papel innato de educadora, la televisión puede enseñarnos conocimiento y transmitirnos valores muy positivos. El problema es que las grandes cadenas apenas explotan esta cualidad. ¿Por qué? Pues porque viven de una publicidad que exige audiencia y la audiencia la registran contenidos, al menos en la actualidad y sin un afán tremendista, que guardan bastante distancia con unos fines educativos.

Por su parte, el telespectador más numeroso no sólo es el que consume este tipo de espacios y los demanda, sino que es quien enaltece los mismos y, en definitiva, alimenta la televisión que hoy tenemos. En ocasiones, hace suyos comportamientos y acciones de quienes ve en la pantalla porque desea ser, vestir y hablar como, relacionarse con y tener lo que y esto, indudablemente, puede mermar la capacidad creativa y contaminar el desarrollo psico-emocional del que consume, claro está, sin digerir, interiorizar, reflexionar y evaluar los mensajes que esconden los medios de comunicación de masas.

A pesar de todo ello, y sin ánimo detractor, no es menos cierto que la televisión, en particular, y los medios, en general, si se consumen con criterio y responsabilidad, fortalecen nuestros mejores valores y logran sacar lo mejor de nosotros mismos, incluso, hasta lo que no somos capaces de hacer o sentir en nuestro ámbito más cercano. Porque la magia de la tele opera como la mejor arma de sensibilización, puede hasta con los corazones más duros. Por eso, al cabo del año nos sorprenden titulares como estos: "Un ciudadano anónimo consigue que un niño almeriense que necesitaba operarse en EEUU de una enfermedad degenerativa pueda hacerlo", "Una gala televisiva logra recaudar fondos para implementar la educación en el Tercer Mundo". Y, por supuesto, también el periodista, el equipo que cubre hechos de esta índole, se empapa de esta acción solidaria y aprende a ser mejor persona.

Por tanto, lo ideal es el equilibrio y el aporte de todos. La clave está en consumir de manera activa, con espíritu reflexivo y crítico, y presionar para que los grandes grupos de comunicación rediseñen sus parrillas y para que tanto los organismos de

\footnotetext{
11 Martínez-Salanova, Enrique, Peralta, Ilda, "Un análisis sobre los medios de comunicación y la solidaridad", en Comunicar, n 15,2000 . Pág. 74.
} 
control de la difusión televisiva como los gobiernos impulsen medidas que saquen partido a una herramienta de transfusión de información y valores tan poderosa como es la Televisión. Como propone Estrella Gualda,

Impregnemos los medios de una ética con rumbo a la solidaridad, como valor que guíe el comportamiento de los profesionales que los dirigen, orientando su acción pública hacia la defensa de la libertad, igualdad y justicia, contribuyendo con ello, desde su ámbito de influencia (que no es poco), a la construcción de un mundo mejor, pero para todos. ${ }^{12}$

En definitiva, a muchos la televisión les ha dado la vida. A otros, se la ha descarrilado. Pensemos ahora, y en base a esto, en sacarle provecho a la potencialidad de un medio como la televisión, en su capacidad de influencia y, sobre todo, en su utilidad como herramienta educadora, concienciadora y sensibilizadora. Mientras tanto, me quedo con el sabio pensamiento de Groucho Marx, que decía que la televisión era muy educativa porque cuando la ponía se iba a leer a otra habitación.

\section{Referencias}

DÍEZ RODRÍGUEZ, Ángeles, "Medios de comunicación y el espectáculo de la miseria”, en Pueblos, 2001. Págs 1-5.

FROUFE QUINTAS, Sindo, "Solidaridad y medios de comunicación: hacia una pirámide de colaboración”, en Aula, no 10, 1998. Págs. 183-193.

GRIJELMO, Álex; Negredo, Samuel, El estilo del periodista, Ediciones Taurus, Madrid, 2001.

GUALDA CABALLERO, Estrella, "Solidaridad y medios de comunicación: una difícil articulación”, en Comunicar, nº 15, 2000. Págs. 21-27.

IGNITIEFF, M, El honor del guerrero. Guerra étnica y conciencia moderna, Ediciones Taurus, Madrid, 1993.

MARTÍNEZ-SALANOVA, Enrique; Peralta, Ilda, "Un análisis sobre los medios de comunicación y la solidaridad", en Comunicar, № 15, 2000. Págs. 71-78.

TABARES CARRASCO, Esteban, "Medios de comunicación, ¿instrumentos para la solidaridad?", en Comunicar, nº 15, 2000. Págs. 37-44.

TERÁN GIMÉNEZ DE CISNEROS, Rafael J, "Solidaridad y medios de comunicación", en Comunicar, nº 15, 2000. Págs. 29-35.

ZUBERO, Imanol, "Las nuevas condiciones de la solidaridad", en Comunicar, nํ 15, 2000. Págs. 15-20.

12 Gualda Caballero, Estrella, "Solidaridad y medios de comunicación: una difícil articulación”, en Comunicar, $\mathrm{n}^{\circ}$ 15, 2000. Pág. 27. 